Abstract

\title{
Performance and Genetic Diversity among a Collection of Stevia Rebaudiana Bertoni Accessions Using Microsatellite Markers in Malaysia ${ }^{+}$
}

\author{
Pedram Kashiani ${ }^{1, *}$, Ghizan Saleh ${ }^{2}$ and Ridzwan Che Rus ${ }^{1}$ \\ 1 Department of Agriculture Science, Sultan Idris Education University (UPSI), Tanjong Malim 35900, \\ Perak, Malaysia; ridzwan@ftv.upsi.edu.my \\ 2 Department of Crop Science, Universiti Putra Malaysia (UPM), Serdang 43400, Selangor, Malaysia; \\ ghizan@upm.edu.my \\ * Correspondence: pedram28july@gmail.com \\ + Presented at the third International Tropical Agriculture Conference (TROPAG 2019), Brisbane, Australia, \\ 11-13 November 2019.
}

Published: 21 April 2020

\begin{abstract}
The plant Stevia rebaudiana Bertoni $(2 \mathrm{n}=22)$ is a native of certain regions of South America particularly in Paraguay. It is a short-term plant and needs three months to complete one cycle of vegetative growth and flowering. With days less than 13 hours in tropical countries, stevia plants flower early, resulting in low yield. In addition, the early bud emergence under the short-day length condition causes the sugar content in stevia leaves to reduce drastically, making them no longer valuable for commercial use. The stevia accessions available in Malaysia today are limited in number and poor in performance, emphasizing the necessity of varietal improvement programs. Assessment of genetic variability, diversity and intrarelationships is an essential step for such breeding programs. This study aims to evaluate agronomic performance of among 21 stevia accessions, namely SRBA-1 to SRBA-21, collected from different origins and to reveal genetic diversity utilizing 52 novel microsatellites. Evaluation of agronomic traits revealed wide range of variation in leaf weight, dry leaf weight, plant height, number of branches, stevioside; rebaudioside A (Reb A), rebaudioside C (Reb C) and total steviol glycosides (TSG). The total genetic diversity detected among the accessions through amplification of the 43 polymorphic microsatellites showed that almost all markers had deviation from Hardy-Weinberg equilibrium $(\mathrm{Ho}>\mathrm{He})$. Three distinct heterotic groups were identified among the accessions based on their agronomic performance and molecular characteristics. Crosses among different accessions coming from different heterotic groups can be further used to produce potential stevia variety for plantation in Malaysia.
\end{abstract}

Keywords: Stevia Rebaudiana Bertoni; Genetic Diversity; Microsatellite Marker

Author Contributions: P.K. and G.S. conceived and planned the experiments. P.K. carried out the experiments, collected and analyzed the data and prepared the manuscript with input from all authors. P.K. and G.S. supervised the experiments and discussed the findings of this work. R.C.R. contributed in data analysis and interpretation of the results.

Funding: This research was funded by Ministry of Higher Education Malaysia, Fundamental Research Grant Scheme number FRGS/1/2014/SG05/UPM/02/9 and The APC was funded by Research Management and Innovation Center, Sultan Idris Education University (UPSI). 
Acknowledgments: The authors would like to thank management and staffs of Agro-Biotechnology Institute Malaysia (ABI) for their support and assistance.

Conflicts of Interest: The author declares no conflict of interest.

(c) 2020 by the authors. Licensee MDPI, Basel, Switzerland. This article is an open access article distributed under the terms and conditions of the Creative Commons Attribution (CC BY) license (http://creativecommons.org/licenses/by/4.0/). 